\title{
EL PAPA BENEDICTO XVI Y EL ÁMBITO INTERNACIONAL
}

\author{
Santiago Petschen ${ }^{1}$ \\ Universidad Complutense de Madrid (UCM)
}

\begin{abstract}
Resumen:
Benedicto XVI, en el conjunto de los papas de los dos últimos siglos, es un papa eminentemente pastoral, poco diplomático. En algunas ocasiones le faltó tacto para manejar sus relaciones con los musulmanes y con los judíos. No le gustaba la política. Como gran pensador de carácter teórico la preocupaba más bien la profundidad de la filosofía que imperaba en Europa, "la dictadura del relativismo". Y también los problemas económicos (el egoísmo del capitalismo financiero) y el medio ambiente que no son política internacional aunque sean contenidos que interesen por sí mismos.
\end{abstract}

Palabras clave: Benedicto XVI, pastorales, diplomacia, relaciones internacionales del Vaticano, política internacional, relativismo.

Title in English: "Pope Benedict XVI and the International Field"

\begin{abstract}
:
Benedict XVI can be presented as an eminently pastoral Pope, not very fond of diplomacy. Sometimes he did not manage with great sophistication the relations between the Roman Catholic Church and Muslims or Jews. He did not like politics. As a theoretical thinker he was worried about the current philosophy that prevails in Europe, "the dictatorship of relativism." He was also very concerned about economic problems (financial capitalism selfishness) and the environment that are very sensitive questions in the present international politics.
\end{abstract}

Keywords: Benedict XVI, pastoral approaches, diplomacy, Vatican international relations, international politics, relativism.

Copyright (C) UNISCI, 2013.

Las opiniones expresadas en estos artículos son propias de sus autores, y no reflejan necesariamente la opinión de UNISCI. The views expressed in these articles are those of the authors, and do not necessarily reflect the views of UNISCI.

\footnotetext{
${ }^{1}$ Santiago Petschen es catedrátido emérito de la Universidad Complutense de Madrid. Email: spetschen@cps.ucm.es.
} 


\section{El Papa Benedicto XVI y el Ámbito Internacional}

La Iglesia católica se ha ido formando a lo largo de la historia como uno de los paradigmas más importantes del cristianismo. Dicho paradigma cuenta como característica muy relevante la de estar muy presente en el ámbito internacional. La base profunda de dicha presencia se encuentra en la voluntad de Jesús, su fundador, que quiso que sus fieles se extendieran por todo el mundo para realizar el objetivo de una vocación universal. En la persecución de dicho objetivo surgieron unas realidades que impactaron en la naturaleza de lo que luego fue el catolicismo. Así, el asentamiento de su cabeza en Roma, capital del Imperio Romano. Después, la marcha del Emperador a Constantinopla con lo que el papa, que empezó a llamarse pontífice, adquirió unas prerrogativas de dignidad y de poder altamente significativas. Luego vino la entrega al papa por parte del rey franco Pipino el Breve del territorio del centro de Italia conquistado a los Lombardos lo que hizo del papa, en el 752, el soberano temporal de los llamados Estados de la Iglesia, con todas sus consecuencias. Ello originó unas competencias y un estilo que impulsaron a la Iglesia a construir una teoría sobre su soberanía de carácter espiritual. Basada en dicha soberanía, muy visible por el hecho de contar con territorio propio, la Iglesia despliega una acción internacional, desarrollando su ius legationis, su ius tractatuum y su presencia en organizaciones y conferencias internacionales, que opera en todas partes del mundo y que origina un acontecer mediático mundial extraordinariamente llamativo.

La Iglesia aprecia y valora mucho la realidad de dicha soberanía y de todo el sistema de actuación que tiene establecido en torno a ella. Tanto es así que la ha cuidado y cultivado con el mismo esfuerzo y esmero que a la doctrina de la salvación que predica dando incluso a veces la impresión de trabajarla con el mismo empeño.

Al decir esto que puede parecer un tanto singular quiero manifestar que el interés pastoral y el interés diplomático de los pontífices se han imbricado con el paso el tiempo, en una especie de paridad tanto monta monta tanto. En los papas de cerca de dos siglos se ha producido una alternancia muy curiosa de carácter pendular entre papa pastoral y papa diplomático.

Recorramos un poco, cronológicamente, los diversos papas para probar lo que decimos. Pio IX fue un papa predominantemente pastoral muy preocupado persistentemente por la observancia de los dogmas. Elaboró y exigió el contenido de un Syllabus de verdades. En su actuación, frente a unas situaciones muy difíciles, operó de forma nada diplomática. $\mathrm{Su}$ sucesor en cambio, León XIII, se lanzó a una acción profundamente diplomática escribiendo unas encíclicas que conectaron a la Iglesia con los problemas del mundo de su tiempo. Pio X volvió al predominio religioso de las condenas y Benedicto XV, el papa de la Primera Guerra Mundial, se entregó a una auténtica actividad internacional a favor de la paz. Pio XI ocupa de nuevo un espacio pastoral. Como nuncio había fracasado en la solución del problema existente entre dos pueblos católicos, el lituano y el polaco. Pío XII optó por la postura diplomática en sus relaciones con los nazis temiendo que una actuación diversa originase grandes daños a la Iglesia. Juan XXIII rompió los moldes de dicha historia pendular. La conexión con los problemas del mundo se realizó por medio de dos importantes encíclicas, la Mater et Magistra y la Pacem in Terris. Y convocó el Concilio Vaticano II para hacer una consideración de la doctrina que llegase mejor a los fieles católicos. Pablo VI, temeroso de que la acción del papa anterior originase desvíos insistió en la recta observancia de la doctrina. Juan Pablo II desarrolló una acción internacional de gran envergadura haciendo más de un centenar de viajes y visitando más de 130 países, algunos de ellos, varias veces. En su 
largo periodo de pontificado se abrieron numerosas nunciaturas apostólicas (embajadas de la Santa Sede).

El contraste existente en la sucesión de los papas (pastoral, diplomático....), lo encontramos también en la relación entre los pontífices y sus secretarios de Estado. De los secretarios de Estado hemos de decir que fueron hombres de gran personalidad que dejaron el recuerdo de haber realizado a favor de la Iglesia acciones de gran importancia. Es el caso de Rampolla con León XIII (mediación entre España y Alemania por la cuestión de las islas Carolinas con la superación del kulturkampf), de Merry del Val con Pío X, de Pietro Gasparri con Benedicto XV y Pío XI (Tratado de Letrán con el nacimiento del Stato de la Città del Vaticano), de Eugenio Pacelli con Pío XI (Concordato alemán, Mit Brennender Sorge), de Jean Villot con Pablo VI, de Agostino Casaroli (la Ostpolitik, la CSCE) y Ángelo Sodano con Juan Pablo II.

Finalizado el breve recorrido que acabamos de hacer, podemos entrar a valorar la práctica y el estilo de la acción internacional de Benedicto XVI. Es tanta la autoridad que la naturaleza de la Iglesia Católica otorga al pontífice que su manera personal de ser tiene gran repercusión en lo que se haga durante su pontificado. Para comprenderlo bien es necesario hacer una referencia al alcance de las relaciones internacionales: su amplísima dimensión, sus facetas múltiples, sus diferentes figuras de representación, sus problemas tanto crónicos como cambiantes. Para afrontar todo ese universo de variadas realidades desde una cima tan eminente y singular como el pontificado, son necesarias unas características especiales: grandes dotes para las relaciones personales, acomodación a la diversidad, empleo de mucho tiempo para los contactos y para las entrevistas. Juan Pablo II dedicaba muchas horas a las audiencias y cuando necesitaba más tiempo utilizaba el destinado a la comida y a la cena. Las invitaciones a su mesa eran constantes.

Benedicto XVI no era persona para tanto movimiento. Como profundo intelectual, necesitaba mucho tiempo para el estudio y la reflexión. Tenía establecido que las visitas que debía tener a lo largo de un día fueran pocas. Es evidente que con tan escasa dedicación, las relaciones internacionales de la Santa Sede tuvieran que verse notablemente afectadas.

Un paralelismo con dicha característica de alejamiento del ámbito internacional aparece en la elección de la persona que fue su secretario de Estado. Recayó en el cardenal Tarcisio Bertone, arzobispo de Génova. La razón efectiva de su nombramiento se debía a que durante siete años había colaborado muy íntimamente con él como secretario de la Congregación para la Doctrina de la Fe de la que el futuro papa alemán era prefecto. El tiempo mostró que dicha elección no podía menos que ser inadecuada. Era una persona carente de experiencia diplomática. Ni siquiera tenía un buen conocimiento del inglés. Pretendió realizar un influjo en Cuba país con cuyas autoridades podía comunicarse en lengua española. Algún analista ha valorado dicho intento como un tanto ingenuo.

Antonio Pelayo, en un artículo publicado en la revista Política Exterior, en su número de marzo-abril de 2013, cuenta que, alarmados por la pasividad de la secretaría de Estado y no solamente por la dimensión de las relaciones con los Estados que acumulan la dimensión propia de un ministerio de Asuntos Exteriores sino por otras facetas, el cardenal arzobispo de Colonia, Joachim Meisner y el cardenal arzobispo de Viena, Christoph Schönborn sugirieron al papa la posibilidad de retirar a Bertone. La respuesta que recibieron fue totalmente negativa. 
Desde tal perspectiva de grandes ocupantes de puestos dirigentes, la del pontífice y la de su secretario de Estado, la relación con la sociedad internacional no podía ser demasiado positiva. En la línea alternante (pastoral ... diplomático), el pontífice Benedicto XVI ha sido lo que le tocaba detrás de Juan Pablo II, muy pastoral y nada diplomático. En cambio, en su relación con el secretario de Estado no buscó generar un aspecto complementario como hicieron otros papas (Pío XI y Pacelli, Pío XII que no quiso tener secretario de Estado sino llevar por sí mismo los asuntos propios de tal cargo), sino tener a un personaje muy parecido a él mismo.

¿Con qué mundo se encuentra Benedicto XVI cuando asciende al solio pontificio? Aspecto preeminente eran las relaciones de Occidente con los musulmanes (tenía lugar entonces la cruenta posguerra de Irak). Existía un problema muy profundo. Es en ese complicadísimo marco cuando Benedicto XVI, en la lección magistral tenida en la Universidad de Ratisbona el 12 de septiembre del 2006, destaca una dimensión muy negativa del Islam frente a la religión cristiana. Y lo hace sirviéndose de una cita del emperador bizantino Manuel II Paleólogo del siglo XIV, en la disputa que tuvo con un persa. La referencia decía: "Muéstrame también aquello que Mahoma ha traído de nuevo y encontrarás solamente cosas malvadas e inhumanas, como su directiva de difundir por medio de la espada la fe que él predicaba". Al examinar lo que significó tan profunda crítica al Islam en la persona del Profeta, en un momento diplomáticamente tan delicado, uno no puede menos que llevarse las manos a la cabeza. Sobre todo después de recordar la acción de Juan Pablo II invitando a los católicos, en cierta ocasión, a unirse a los musulmanes en la práctica del ayuno en el último día del Ramadán. O la calurosa acogida que le deparó Hasan II, en su visita a Maruecos, invitándole a hablar a los jóvenes musulmanes que llenaban el estadio de Casablanca el día 19 de agosto de 1985. Juan Pablo II llegó a ser en el mundo islámico bastante popular. Benedicto XVI se dio, con su conferencia de Ratisbona, un enorme batacazo.

Después de aquella desafortunada intervención, Benedicto XVI hizo esfuerzos para que aquel malestar que se había producido con la difusión de su texto se modificara. Pero sólo lo logró muy parcialmente con la celebración en el Vaticano de una cumbre católico-musulmana y la visita al papa del rey de Arabia Saudita en noviembre de 2007. Había dado ya la vuelta al mundo con efectos imparables. Se apuntaron a la crítica primeros ministros y ministros de Asuntos Exteriores. Y en muchos lugares fueron las masas las que protestaron. En algún lugar la efigie del pontífice fue quemada en público.

En el mundo de hoy la imagen tiene una importancia extraordinaria. Benedicto XVI pareció no haber caído suficientemente en la cuenta de ello. La elección de aquella cita fue totalmente desafortunada. La profundidad del daño causado no se pudo reparar a pesar de que en los viajes que hizo por el mundo musulmán acudía a rezar a las mezquitas. Es un vivo ejemplo de lo que puede pasarle a una persona demasiado teórica. Le ocurre lo que al cazador que tiene un dominio muy seguro de su escopeta pero que luego, en lugar de disparar al ciervo, dirige la bala sin darse cuenta al perro. En consecuencia de ello fue llamado por determinados medios de comunicación, torpe, impolítico y carente de habilidad diplomática. Ello no quiere decir que el papa no propusiera al Islam objetivos adecuados como hacer una evolución parecida a la del cristianismo a partir de la Ilustración.

Ratzinger es una personalidad de gran talento teórico. Es autor de más de treinta obras. Una de ellas, la Introducción al cristianismo está traducida a 20 lenguas. Sin embargo, en las cuestiones prácticas puede perderse y conseguir lo opuesto a lo que pretendía. De haberse imaginado lo que iba a pasar, nunca hubiera pronunciado aquella frase de un emperador del 
siglo XIV. Cualquier asesor, por poco avispado diplomático que fuera, le hubiera aconsejado suprimirla. Mas, como intelectual, él era quien transmitía el producto de su convicción. El desliz no tuvo consecuencias sólo para él sino también para las minorías cristianas, tanto católicas como no católicas, que viven en los países musulmanes. En defensa de tales minorías tuvo que tomar frecuentemente la palabra lo que daba la sensación de estar en una permanente situación de tensión y de desafío.

En el abordar de los asuntos del mundo musulmán, Benedicto XVI optó por intervenir con toda claridad. Durante la posguerra en Irak no dejó de insistir a las partes en que cesaran en el uso de la violencia. Condenó el muro levantado por los israelíes encerrando al territorio cisjordano y ahogando el vivir cotidiano de la ciudad de Belén. Condenó también las operaciones de los israelíes en el Líbano por afectar a objetivos civiles. En la cuestión de las caricaturas se inclinó por condenar la falta de respeto a los símbolos religiosos en contra de aquellos que no ponen límites a la libertad de opinión.

En sus relaciones con los judíos, Benedicto XVI, sin embargo no fue un exitoso diplomático. Debemos recordar que algunas importantes reclamaciones de la Santa Sede no se logran, como la restitución de la sala del Cenáculo y la conservación de los poblados cristianos de Tierra Santa, alguno de los cuales ha desaparecido bajo la acción de las excavadoras. Hubo decisiones del pontífice que impactaron negativamente en la sociedad judía. Así fue por ejemplo la rehabilitación del obispo Williamson, negador del Holocausto judío, el impulso a la beatificación del papa Pío XII, considerado como un Papa santo, pero de triste memoria en la sociedad judía y cuyo retrato es mantenido en el museo del Holocausto. La vuelta a la misa tridentina en la que se reza una oración por la conversión de los judíos. Todo ello es indicio de que las posiciones católicas se asumen con toda la fuerza, pero que no se tiene en cuenta la repercusión pública que ellas puedan tener. Estas actuaciones no hicieron tanto daño a las relaciones católico-judías como la conferencia de Ratisbona hizo a las católico-islámicas. Los judíos las han excusado por estar muy interesados en mantener muy buen trato con el catolicismo. No en vano pertenecen a la misma civilización occidental. Una figura eminente, el rabino David Rosen, responsable del diálogo interreligioso para el American Jewish Committee escribió de forma muy laudatoria sobre Benedicto XVI. Destacó el hecho de que en las reuniones de Asís el papa tomara asiento en igualdad con el de los demás participantes.

Una exposición de la visión que Benedicto XVI tiene acerca de lo que debe ser la realidad internacional y de los principios por los que debe regirse, la tenemos en el discurso que pronunció ante la Asamblea General de las Naciones Unidas el 18 de abril del año 2008. El pilar fundamental de la doctrina defendida por el pontífice fue la defensa y la protección de los derechos humanos. Dichos derechos son los derechos básicos de las personas. Son la manifestación de la profunda dignidad de la persona humana. Es la defensa de esa dignidad la finalidad última del derecho internacional. El pontífice advirtió contra ciertas persuasiones y prácticas que deben ser superadas por no resultar adecuadas para la defensa del ser humano. Así por ejemplo la aplicación de ciertas normas establecidas por la legalidad haciéndolas prevalecer sobre la justicia. O el no impedir determinados actos que obstaculizan la realización efectiva del desarrollo de la persona humana comprometiendo de esa manera su dignidad.

Refiriéndose a lo que él mismo ha denominado "la dictadura del relativismo" manifestó que las verdades deben ser siempre tenidas en cuenta por encima de los resultados obtenidos en los consensos. De esa forma criticó la utilización del mero pragmatismo en las relaciones internacionales. En su discurso no se mantuvo en el plano teórico sino que bajó a reglas del 
quehacer cotidiano insistiendo en el cumplimiento del principio agustiniano "no hagas a otros lo que no quieras que te hagan a ti”.

Acerca de las Naciones Unidas como Organización Internacional pidió para ella un papel más fuerte como autoridad mundial. Insistió en la obligación moral que tiene de actuar frente a las acciones de gobiernos criminales. Ningún país, dijo el papa, debe arrogarse el papel de imponer a los demás por la fuerza su punto de vista por muy adecuado que le parezca. Son los organismos internacionales los que deben desempeñar el papel de dirigentes. Dichos organismos están hechos para actuar por encima de los Estados y deben presionar a los gobiernos para que cumplan con su obligación de proteger a los ciudadanos. Mostró el papa cierta desconfianza hacia las superpotencias. No son ellas las que deben solucionar los problemas de la sociedad internacional. El mundo de nuestros días está exigiendo que sea la comunidad internacional, es decir, los Estados conjuntos organizados quienes impongan su concepción de lo justo en las determinadas circunstancias en que le toque actuar. Para la solución de los conflictos debe tener en cuenta siempre las potencialidades que llevan consigo el diálogo y la reconciliación.

Estas reflexiones que hizo Benedicto XVI ante la Asamblea General de las Naciones Unidas son una reflexión directa sobre las relaciones internacionales de nuestros días. Unos principios generales que deben ser aplicados por ser fundamentales y necesarios. Por tener un componente teórico importante, Benedicto XVI ha sabido afrontarlos con toda su riqueza sin olvidar nada que tenga valor. No olvidemos que la revista Foreign Policy en el año 2009 clasificó a Benedicto XVI en el lugar 17 entre los "100 mayores pensadores globales del año".

Acudiendo sin embargo a la realidad internacional y a sus problemas cotidianos vemos que Benedicto XVI rehuye tratar problemas de ese estilo. Da la impresión que la política no le gusta. Le gusta el trato de los problemas profundos. Así por ejemplo, cuando habla de Europa busca referirse más bien a aspectos filosóficos y morales de la sociedad europea como el nihilismo, el relativismo, el secularismo agresivo. Quienes han querido hablar de la presencia de Benedicto XVI en la escena internacional, como ha hecho por ejemplo el nuncio Juan Pablo Somiedo, ha tenido que referirse no a problemas directamente políticos sino a cuestiones de carácter económico o de defensa del medio ambiente. Estas cuestiones están íntimamente relacionadas con la política internacional pero no son por sí mismas política internacional. Son dos contenidos que interesan por sí mismos.

El primero de ellos es una crítica al capitalismo financiero controlado desde el más demoledor interés del egoísmo. Ello lleva a unas consecuencias del todo dramáticas. Hablando de África el papa Ratzinger protesta contra la grave situación de pobreza que afecta a los habitantes de prácticamente todo el continente.

Otro tema en el que la dimensión intelectual de Benedicto XVI ha escogido como objeto de pensamiento ha sido el del medio ambiente. Afecta a toda la Humanidad y la forma de tratarlo puede generar unas injusticias verdaderamente grandes. El trato adecuado del medio ambiente, por el contrario, puede ser un factor importante a favor del progreso de todos y del equilibrio social de todo el género humano.

Los demás problemas a los que la Santa Sede se ha dedicado dentro del ámbito de las relaciones internacionales son muy concretos y tienen una dimensión más bien eclesiástica si los enfocamos desde el punto de vista de los intereses. Nos referimos a dos cuestiones. Una de ellas es Cuba y la otra China. Los logros en Cuba se han producido en lo referente a la libertad religiosa y en la devolución a la Iglesia de algunos edificios. Con respecto a China se 
ha reconocido la existencia de una mayor disposición a dialogar por ambas partes. El tiempo dirá si la llegada al poder del nuevo papa Francisco y de quien nombre como secretario de Estado suponga algún cambio más efectivo en las relaciones del gigante asiático con la Santa Sede. 